\title{
Projeto alternativo de desenvolvimento rural sustentável
}

\author{
MANOEL JOSÉ DOS SANTOS
}

\section{Desenvolvimento mediante ampla e massiva reforma agrária, com valorização e fortalecimento da agricultura familiar}

$\mathrm{O}$ PROCESSO de modernização da agricultura brasileira - conservador, parcial, excludente e ecologicamente insustentável - acelerou a exclusão social e a degradação ambiental no campo brasileiro, incrementando a luta por reivindicações históricas do Movimento Sindical dos Trabalhadores e Trabalhadoras Rurais (MSTR), que surgem para superar os prejuízos sociais e políticos causados pelo modelo agrário e agrícola imposto ao país. Este processo de desenvolvimento e as recentes transformações no meio rural, mantendo o seu caráter concentrador de terra e renda, criam demandas e exigem respostas cada vez mais complexas por parte do movimento sindical.

Desde a sua origem, o MSTR tem entre seus eixos de atuação a elaboração e a luta por propostas que possibilitem a melhoria das condições de vida das populações do campo. As lutas históricas têm buscado a valorização do espaço rural como um local privilegiado de transformação e implementação de políticas de inclusão social com profundas repercussões sobre o conjunto da sociedade brasileira. Foi com esse espírito que a Confederação Nacional dos Trabalhadores na Agricultura (CONTAG), ao longo de sua história, empunhou as bandeiras da luta pela reforma agrária, por uma política diferenciada para a agricultura familiar e pelos direitos dos assalariados rurais.

A busca de alternativas ao atual modelo de desenvolvimento motivou os delegados e delegadas do $6^{\circ}$ Congresso Nacional de Trabalhadores Rurais, realizado em 1995, a iniciar o debate e a afirmar a necessidade de formular um Projeto Alternativo de Desenvolvimento Rural Sustentável. Este debate teve continuidade em várias iniciativas de âmbitos nacional, estadual, regional e municipal. Os seminários regionais de desenvolvimento alternativo, promovidos pela Confederação em 1996, e a realização do projeto de pesquisa e formação da Central Única dos Trabalhadores (CUT)/CONTAG, foram momentos ímpares de elaboração e sistematização de propostas. 
O $7^{\circ}$ Congresso Nacional de Trabalhadores e Trabalhadoras Rurais, realizado em 1998, aprovou os pontos centrais que deveriam nortear a construção e implementação do PADRS, que são apresentados a seguir.

As mobilizações do Grito da Terra Brasil têm constituído um espaço privilegiado de formulação e articulação das demandas por políticas voltadas para um novo desenvolvimento no campo.

\section{Elementos centrais do Projeto Alternativo de Desenvolvimento Rural Sustentável (PADRS)}

O ponto de partida para a elaboração e implantação de um projeto alternativo é a concepção de desenvolvimento. Até recentemente havia uma identificação entre desenvolvimento e crescimento econômico. Isto permitia que o desenvolvimento dos países fosse medido apenas pelos níveis da renda per capita. Esta identificação, porém, tem sido amplamente contestada, especialmente porque crescimento e desigualdade social têm andado lado a lado. Análises que levam em conta apenas a renda per capita mascaram o grau de concentração da riqueza numa sociedade.

O debate sobre o significado real de desenvolvimento levou a estudos para estabelecer parâmetros capazes de avaliar o nível de vida das pessoas de uma forma mais adequada. A criação do Índice de Desenvolvimento Humano (IDH) é fruto deste esforço por uma melhor avaliação da qualidade de vida em cada país. Este índice inclui três dimensões básicas de desenvolvimento: longevidade (viver uma vida longa e saudável), conhecimento (ser instruído) e padrão de vida (gozar de um nível de vida adequado). A partir daí foram criadas três variáveis para medir o desenvolvimento humano em diferentes países: esperança de vida, nível educacional (alfabetização de adultos e escolaridade nos três níveis) e PIB real per capita.

Entendemos, portanto, que o desenvolvimento deve incluir crescimento econômico, justiça, participação social e preservação ambiental. Este desenvolvimento privilegiaria o ser humano na sua integralidade, possibilitando a construção da cidadania. Neste caso, as questões econômicas têm de estar articuladas às questões sociais, culturais, políticas, ambientais e às relações sociais de gênero e raça.

O que leva o movimento sindical dos trabalhadores e trabalhadoras rurais ao esforço de construir um projeto de desenvolvimento é, então, justamente a esperança de uma vida melhor para os que vivem no campo e não possíveis sonhos ou fantasias sobre as chances dos países semiperiféricos entrarem no Primeiro Mundo, ou sobre a possibilidade de generalização dos padrões de vida do núcleo central.

Não se alcança tal desenvolvimento ou "esta vida melhor" com programas de combate à pobreza. Os problemas do campo são de ordem econômica, de acesso aos mercados e de políticas voltadas para o desenvolvimento das suas po- 
pulações. Programas de "assistência social” são incapazes de gerar renda, aumentar a auto-estima das populações rurais e, portanto, gerar desenvolvimento. Por isso é fundamental criar políticas e programas voltados para a distribuição de renda. Segundo estudos realizados por Ricardo Paes de Barros, pesquisador do IPEA, um crescimento contínuo de $5 \%$ ao ano no Brasil levaria a uma redução de 13\% no grau de pobreza em uma década. Seus estudos demonstraram a importância da criação de políticas com cunho distributivo, e não apenas de programas assistenciais de erradicação da pobreza.

É importante também salientar que existem cada vez maiores evidências de que o próprio crescimento dos países chamados de economia semiperiférica depende da redução das desigualdades. Vários estudos econométricos demonstraram que níveis de desigualdade, como os do Brasil, dificultam ou mesmo impedem o crescimento econômico. Baseado nestes estudos, o diretor do Instituto de Desenvolvimento Social do BID afirmou que "a redução das desigualdades, além de ser fundamental para uma sociedade e básica para uma democracia, é estratégica para a obtenção de desenvolvimento real e sustentado".

O MSTR entende que não há desenvolvimento no meio rural sem educação, saúde, garantias previdenciárias, salários dignos, erradicação do trabalho infantil e escravo, respeito à autodeterminação dos povos indígenas e preservação do meio ambiente. As lutas dos trabalhadores e trabalhadoras pela terra, política agrícola diferenciada, políticas sociais e direitos trabalhistas inserem-se, portanto, na construção de um projeto alternativo de desenvolvimento baseado na expansão e no fortalecimento da agricultura em regime de economia familiar.

O eixo central das estratégias deste desenvolvimento - preconizadas pelo movimento sindical - é a amplûûção das oportunidades de emprego e renda no meio rural. Ocupa lugar privilegiado nestas estratégias a realização de uma ampla reforma agrária, como um instrumento fundamental na expansão, no fortalecimento e na viabilização da agricultura familiar.

A geração de emprego e renda não se resume, evidentemente, à expansão e ao fortalecimento da agricultura familiar. Ela inclui a melhoria das condições de vida de imensos contingentes de assalariados agrícolas e a criação de outras ocupações rurais não-agrícolas e "urbanas" no campo.

Da mesma forma, não é possível pensar em qualidade de vida, sem que haja preocupação com a qualidade do ambiente em que as pessoas vivem. É preciso também pensar em soberania alimentar, padrões de desenvolvimento agrícola diversificados e sustentáveis a longo prazo, que restaurem as condições ecológicas da produção e respeitem o potencial de cada ecossistema, apoiando-se nas bases científicas da agroecologia.

Neste sentido, é essencial qualificar o debate e o entendimento dos trabalhadores e trabalhadoras rurais sobre a relação entre meio-ambiente, qualidade 
de vida e desenvolvimento, fortalecendo novas relações entre os seres humanos e a natureza.

\section{A luta pela reforma agrária}

A reforma agrária, neste contexto, é o principal instrumento político para a ruptura com o atual modelo de desenvolvimento excludente, concentrador de terra e renda e reprodutor do poder oligárquico. É um instrumento essencial para promover o desenvolvimento democrático da agricultura e o resgate da cidadania para milhões de trabalhadores e trabalhadoras que, expulsos da terra, se viram excluídos do processo produtivo. É preciso uma política séria de Reforma Agrária que possibilite oferecer a 4,8 milhões de famílias sem terra a oportunidade de ingressar no regime de agricultura familiar.

A democratização da propriedade da terra impulsiona a democratização do poder político, econômico e social. Promove a geração de emprego e ocupações produtivas para todo um segmento sem alternativas de inserção social e produtiva, a eqüidade, sustentabilidade ambiental, e o desenvolvimento das comunidades envolvidas, processos essenciais para o fortalecimento da agricultura familiar e a construção de alternativas de desenvolvimento para o Brasil.

A realização de uma verdadeira reforma agrária deverá tocar, portanto, nos pilares que fundamentam a exclusão social e o frágil desenvolvimento brasileiro, promovendo a inclusão social, a formação e a consolidação de um forte mercado interno no país. Um amplo processo de mobilização de massa, a exemplo da ocupação dos latifúndios improdutivos, força as desapropriações e quebra a espinha dorsal do conservadorismo, pois ataca o poder econômico e político dos latifundiários. Aliada à imediata regularização das terras ocupadas por posseiros e posseiras, a implantação de um programa de crédito fundiário e de um massivo apoio à consolidação da agricultura familiar são fundamentais na construção de alternativas de desenvolvimento.

A expansão da agricultura familiar depende de uma política agrária abrangente, que permita o acesso à terra a todos os trabalhadores e trabalhadoras, sem terra ou com terra insuficiente para assegurar o seu desenvolvimento, sob o prisma da eqüidade, sustentabilidade e competitividade. Esta política de redistribuição é ainda mais necessária nas regiões com maior concentração fundiária.

A consolidação dos assentamentos de reforma agrária representa a passagem dos trabalhadores e trabalhadoras de um quadro de exclusão para o de inserção produtiva. Para tanto, são necessárias linhas de crédito especiais, assistência técnica e investimentos em infra-estruturas social e produtiva, voltadas à organização da produção e ao bem-estar das famílias assentadas. A formação profissional e os instrumentos de política de desenvolvimento, como crédito, 
entre outros, devem ser aplicados imediatamente após o assentamento dos trabalhadores e trabalhadoras. Devem também ser garantidos recursos orçamentários para a cobertura do total de assentamentos realizados no país, bem como a imediata legalização da área.

Portanto, a reforma agrária só terá sustentabilidade econômica e social se estiver inserida num contexto de políticas globais de valorização e ampliação do papel estratégico da agricultura em regime de economia familiar para o desenvolvimento do país.

\section{A agricultura familiar e a potencialização do desenvolvimento}

A opção pela agricultura familiar justifica-se por sua capacidade de geração de emprego (da família e de outros) e renda a baixo custo de investimento. A sua capacidade de retenção da população fora dos grandes centros urbanos é fator fundamental na construção de alternativas de desenvolvimento. Sua capacidade de produzir alimentos a menor custo e, potencialmente, com menores danos ambientais, impulsiona o crescimento de todo o entorno sócio-econômico local. A falta de incentivos à agricultura familiar tem gerado a marginalidade dos jovens trabalhadores e trabalhadoras, envolvendo-os em drogas, prostituição, gravidez precoce etc.

Os dados divulgados pelo Incra nos resultados da pesquisa "Novo Retrato da Agricultura Familiar: o Brasil redescoberto", realizada em parceria com a FAO sob a coordenação de Carlos Enrique Guanziroli e Silvia Elizabeth de C.S. Cardim, com base nos dados do Censo Agropecuário do IBGE de 1995-96, deram conta que, no Brasil existiam 4.859.864 imóveis rurais cadastrados que ocupavam uma área de 353,6 milhões de ha.

Desse total, 4.139.369 eram estabelecimentos familiares, ocupando uma área de 107,8 milhões de ha, representando $30,5 \%$ da área total e $85 \%$ dos estabelecimentos. Responsáveis por 37,9\% do Valor Bruto da Produção, haviam recebido apenas $25,3 \%$ do financiamento destinado a agricultura, apesar de terem se mostrado mais eficientes no uso do crédito, pois produziram mais com menos recursos. Segundo essa mesma pesquisa, "o financiamento destinado a agricultura é desproporcional entre os agricultores familiares e patronais, sendo que em todas as regiões a participação dos estabelecimentos familiares no crédito rural é inferior ao percentual do Valor Bruto da Produção [pelo] que eles são responsáveis."

A pesquisa constatou ainda que "os agricultores familiares produzem $24 \%$ do Valor Bruto da Produção da pecuária de corte, $52 \%$ da pecuária de leite, $58 \%$ dos suínos, e $40 \%$ das aves e ovos produzidos. Em relação a algumas culturas temporárias, a agricultura familiar produz 33\% do algodão, $31 \%$ do arroz, $72 \%$ da cebola, $67 \%$ do feijão, $97 \%$ do fumo, $84 \%$ da mandioca, $49 \%$ do milho $32 \%$ da 
soja, $46 \%$ do trigo, $58 \%$ da banana, $27 \%$ da laranja, $47 \%$ da uva, $25 \%$ do café e $10 \%$ da cana de açúcar.”

A agricultura é portanto o principal agente propulsor do desenvolvimento comercial e, conseqüentemente, dos serviços nas pequenas e médias cidades do interior do Brasil. Basta criar incentivos à agricultura para que, pelo seu efeito multiplicador, se obtenha respostas rápidas nos outros setores econômicos. É também condição fundamental para que haja uma sobrevida para a economia da grande maioria dos municípios brasileiros. É o desenvolvimento com distribuição de renda no setor rural que viabiliza e sustenta uma qualidade de vida do setor urbano.

Segundo pesquisa recentemente realizada pela CONTAG/CUT em várias áreas do país, a agricultura familiar ainda é a forma preponderante de produção agrícola. Se devidamente apoiada por políticas públicas e ancorada em iniciativas locais, pode se transformar no grande potencializador de um desenvolvimento descentralizado e voltado para uma perspectiva de sustentabilidade.

O desenvolvimento e o fortalecimento da agricultura familiar dar-se-á pela implementação de diversas iniciativas, que deverão estar interligadas para que possam produzir os efeitos desejados. O Programa Nacional de Apoio à Agricultura Familiar (PRONAF) e os Fundos Constitucionais são algumas iniciativas, não podendo, entretanto, a ação estatal se esgotar apenas na disponibilização de recursos para crédito de custeio. É fundamental agilizar os procedimentos das linhas de crédito de custeio e investimento, assim como a reformulação de toda a infra-estrutura produtiva e social, para atender às necessidades da agricultura familiar de forma que possa ter facilitado o seu acesso aos mercados.

As políticas de apoio à agricultura familiar devem, inclusive, contemplar aquelas atividades não-agrícolas, como a industrialização, a produção artesanal e o turismo rural, atividades com grande potencial de geração de renda e ocupação. Outro elemento que deve estar integrado às políticas fundamentais de fortalecimento da agricultura familiar diz respeito à priorização de investimentos públicos para garantir serviços de pesquisa, experimentação, difusão, assistência técnica e extensão rural, comprometidos com a sustentabilidade e adaptados aos meios de produção familiar.

Existe um conjunto de iniciativas para o fortalecimento da agricultura familiar que depende muito da ação sindical, como por exemplo, organização, comercialização e gestão da produção, diversificação agroecológica e planos de desenvolvimento local. Este conjunto de proposições deve estar articulado a uma política de produção de alimentos e soberania alimentar da população brasileira, como parte integrante da estratégia de desenvolvimento.

Por outro lado, a gestão da unidade produtiva precisa ser considerada como o exercício prático da democracia. Se todos os membros da família têm um papel 
e uma função no processo produtivo, têm direito a tomar parte nas decisões e nos resultados. Para isso, é preciso valorizar o trabalho das mulheres e dos jovens na agricultura em regime de economia familiar, construindo relações sociais de gênero, geração e etnia igualitárias e solidárias no cotidiano dos trabalhadores e trabalhadoras. É preciso também entender que a agricultura familiar só se viabiliza a partir de uma economia solidária. Neste sentido, a gestão coletiva da produção se apresenta como uma alternativa concreta, pela prática da cooperação:

- a agricultura familiar só se viabiliza a partir de uma economia solidária, combinada com o uso de novas tecnologias e diversificação dos meios tradicionais de produção;

- as formas coletivas de produção e comercialização se apresentam como alternativas concretas mediante a prática de cooperação, associativismo e parceria;

- desenvolvimento rural sustentável passa necessariamente pela garantia de documentação do uso da terra, o que também contribui para a construção da cidadania da população rural.

\section{Assalariados rurais}

O Projeto Alternativo de Desenvolvimento Rural Sustentável, deve ter como uma das suas principais características a ampliação da oferta de emprego e ocupações produtivas no campo. Neste sentido, ele é estratégico para os assalariados e assalariadas rurais, uma vez que amplia as oportunidades de trabalho existentes.

O Brasil tem hoje cerca de cinco milhões de assalariados rurais. Em que pese o processo de reestruturação produtiva e o aumento crescente do desemprego, este número deve permanecer significativo nos próximos anos, constituindo assim a maior base de assalariados rurais do mundo.

A construção de alternativas de desenvolvimento com base na expansão e fortalecimento da agricultura familiar não irá eliminar, por si só, a agricultura patronal. Não representará, portanto, o fim do assalariamento rural. Este continuará existindo e demandando políticas específicas para o setor.

Por outro lado, a realidade demonstra que muitos agricultores e agricultoras familiares dependem de contratação de mão-de-obra externa para garantir o desenvolvimento de sua produção. Esta realidade vem sendo objeto de muitas discussões no movimento sindical, pois demanda políticas e participação diferenciadas na base sindical.

Qualquer projeto alternativo de desenvolvimento deve pressupor a democratização nas relações de trabalho, renda digna e respeito aos direitos trabalhistas, como condições básicas para a qualidade de emprego e vida, independentemente de quem quer que seja o empregador. 
Os assalariados rurais constituem a parcela mais empobrecida da agricultura e, por decorrência, de toda população brasileira. As alternativas de desenvolvimento devem abarcar este setor, interferindo diretamente na criação de novos postos de trabalho, reduzir o desemprego e criar melhores condições de vida e trabalho, e melhores salários, priorizando as seguintes questões:

- assentamento de trabalhadores e trabalhadoras rurais assalariados, em especial os desempregados e subempregados que optarem por desenvolver a sua própria agricultura mediante um programa de reforma agrária;

- criação de agroindústrias ligadas à agricultura familiar, com legislação específica;

- geração de emprego no interior da unidade produtiva familiar;

- programas de qualificação profissional e reconversão produtiva;

- campanhas de educação e prevenção sobre uso de agrotóxicos e suas conseqüências, garantindo o atendimento aos trabalhadores e trabalhadoras envolvidas nessa atividade.

\section{Formulação de políticas sociais para o campo}

As políticas sociais desempenham um papel fundamental na construção de alternativas de desenvolvimento para o campo. Educação, saúde, lazer, previdência e assistência social, formação profissional, pesquisa e assistência técnica são elementos estruturais de qualquer proposta de desenvolvimento.

Em um mundo em constante mutação, onde a questão tecnológica assume papel preponderante na capacidade de integrar-se ao sistema produtivo, é preciso uma mudança radical do ambiente educacional até agora oferecido aos trabalhadores e trabalhadoras rurais. É necessário estabelecer uma maior relação entre ensino regular básico, formação profissional, redes de extensão rural e assistência técnica e suas relações com a pesquisa.

Seja para a plena promoção da cidadania entre as populações rurais, seja para o próprio incremento da capacidade produtiva dos agricultores, é fundamental que se eleja como uma das prioridades, o desenvolvimento de políticas educacionais no meio rural, como uma das condições básicas para o desenvolvimento sustentável. Nenhuma comunidade, cidade ou país poderá alcançar o pleno desenvolvimento sustentável sem uma política educacional sólida, que seja capaz de aumentar a auto-estima da sua população, promovendo a cidadania, a participação social e a capacidade técnica de produzir.

Também são objetivos estratégicos de um projeto de desenvolvimento a inclusão de valorização das tradições e dos bens culturais produzidos pela população: melhoria dos níveis de alfabetização, reestruturação e mudança curricular de $1^{\circ}$ grau, voltadas à realidade rural, políticas de preservação e implantação de 
novas escolas e maior integração das propostas de ensino técnico dos agricultores e agricultoras com as políticas de pesquisa e extensão rural (também reordenadas no sentido de aproximá-las das reais necessidades dos agricultores e agricultoras familiares).

A efetiva implementação do Sistema Único de Saúde (SUS) é o caminho correto para assegurar atendimentos médico, odontológico e hospitalar adequados às necessidades das populações rurais, que exigem formulações e atendimentos mais específicos, face às próprias características de localização em que se encontram. Além de a luta pela manutenção do SUS, no entanto, é preciso redirecionar o investimento público em saúde para ações estruturadoras de médio e longo prazos, para a melhoria da qualidade de vida egarantia do bem-estar social da população.

O acesso dos trabalhadores e trabalhadoras rurais aos benefícios da Previdência e Assistência Social é fundamental para o resgate da dignidade e cidadania de milhões de pessoas. Além disso, os recursos da aposentadoria têm se mostrado um importante instrumento de transferência de renda para o interior do país, chegando a ser fator de dinamização de diversos municípios. Esta tendência reverte, em parte, a orientação histórica de transferência de recursos do setor rural para o setor urbano.

Embora a aposentadoria constitua, em parte dos municípios rurais, a principal fonte de renda e, portanto, um elemento propulsionador do desenvolvimento local, mais de um milhão de pessoas tiveram seus benefícios represados e indeferidos pela burocracia do INSS no período de 1994 a 1997. Alternativas de desenvolvimento pressupõem, portanto, a defesa dos direitos sociais e políticos da população rural na terceira idade.

\section{Relações de gênero e geração no meio rural}

Pensar um projeto de desenvolvimento alternativo e sustentável requer repensar as relações sociais constituídas e as suas estruturas organizativas. O sucesso deste projeto está condicionado pela legitimação e valorização social dos diversos sujeitos envolvidos, ou seja, mulheres, homens, jovens, crianças, idosos, deficientes e excepcionais. Para isso, é preciso dar visibilidade a todos, principalmente às mulheres e aos jovens.

Todos os setores agrícolas, especialmente a agricultura familiar, incorporam massivamente o trabalho da mulher na esfera produtiva. A inclusão de uma abordagem de gênero é fundamental no projeto, introduzindo uma nova concepção nas relações entre homens e mulheres. Estas relações devem possibilitar a participação efetiva das mulheres na tomada de decisões e construção de políticas alternativas de desenvolvimento. 
Da mesma forma, é fundamental o reconhecimento dos jovens e idosos como atores sociais e produtivos. Apesar de a importância das lutas econômicas, é preciso combater todas as raízes da exclusão social para que possamos, de fato, avançar na construção de uma nova sociedade. Para tanto, torna-se necessário criar políticas específicas especialmente para os jovens no meio rural (oportunidades de emprego, lazer, formação, educação com currículo adequado à realidade rural) e garantir espaços de participação, promovendo assim a construção das bases culturais de um novo tipo de desenvolvimento.

\section{Formulação de um projeto amplo e construção de alianças}

A construção de um projeto alternativo é uma ação permanente de elaboração de propostas e de ações estratégicas. É preciso, portanto, buscar articular o acúmulo teórico e prático do movimento sindical e de seus parceiros e aliados, em suas diversas instâncias e organizações. A ação sindical deve combinar, ao mesmo tempo, a negociação, a mobilização social e a luta política no âmbito de um movimento sindical propositivo e atuante.

A formulação deste projeto deve facilitar a coesão e a articulação dos diversos segmentos e espaços de representação da CONTAG e do conjunto do MSTR, mas sem se limitar apenas à sua base sindical. Ele articula e é articulado por uma estratégia democrática de desenvolvimento global que, além de garantir a inclusão social, possibilita a produção e a reprodução da qualidade de vida para o conjunto da sociedade.

O crescimento econômico nas cidades, por mais forte que venha a ser, será incapaz de reduzir ou estabilizar o atual desemprego urbano e suas conseqüências diretas: fome, miséria, marginalização e violência. Qualquer anseio de desenvolvimento sustentável global para o país será mero sonho se não partir da ampliação das oportunidades de geração de renda no meio rural. Por outro lado, a permanente disputa de hegemonia com os setores dominantes exige a formulação de propostas amplas, na busca de unificar as lutas na construção de alternativas para todos os trabalhadores e trabalhadoras brasileiras.

A elaboração e implementação deste projeto alternativo exige, portanto, um amplo processo de alianças. A discussão de suas diretrizes, propostas e lutas deve se dar de forma conjunta com o movimento sindical urbano, técnicos e intelectuais e os diversos movimentos e organizações da sociedade civil.

\section{Estratégia do MSTR para construção e consolidação de um projeto alternativo de desenvolvimento rural sustentável}

Nós nos propomos, a partir de nosso espaço de atuação - o setor rural - a organizar os trabalhadores e trabalhadoras para a luta. E para disputar a hegemonia 
na sociedade, para chegar a transformações capazes de garantir melhores condições de vida e trabalho para todos, resgatando a cidadania nestes e em todos os espaços sociais.

Isto porque, já não basta somente a denúncia e a contestação. A luta contra o neoliberalismo não possui contornos tão nítidos como outrora. É preciso mais que simples reivindicações pontuais. Assim, o MSTR articula-se para apresentar um conjunto de diretrizes em torno da implementação de um Projeto Alternativo de Desenvolvimento Rural Sustentável. Entendemos, porém, que esse Projeto por sí só não será capaz de abarcar todas as mudanças e transformações necessárias para que ele se viabilize. É preciso uma articulação maior com os setores urbanos para a construção de um Projeto de Desenvolvimento Sustentável para o país em que o Projeto Alternativo de Desenvolvimento Rural Sustentável se inserisse.

Este desenvolvimento estaria estruturado em dois eixos estratégicos: a realização de uma ampla e massiva reforma agrária e a consolidação e valorização da agricultura familiar, e uma profunda mudança no ordenamento econômico que possibilitaria a inclusão social tanto dos trabalhadores e trabalhadoras rurais, quanto dos urbanos.

A estratégia do MSTR deverá estar articulada com o enfrentamento ao projeto neoliberal, suas conseqüências e seus gestores, e com a reorganização sindical, buscando maior organicidade, democracia e transparência às estruturas e às ações. Isto só será possível combinando-se um conjunto de iniciativas e ações, entre elas a necessidade de dar continuidade e visibilidade à elaboração do Projeto Alternativo de Desenvolvimento Rural Sustentável, fazendo dele um instrumento de proposição clara para as novas diretrizes contra a miséria e a exclusão social.

Esta ação propositiva deverá obrigatoriamente estar articulada a um processo intenso de luta e mobilização popular - que ocorre nos espaços rurais - por intermédio da organização dos Gritos da Terra Brasil, campanhas salariais, ocupações de latifúndios, pressão aos órgãos públicos, lutas de aposentados, jovens, crianças, entre tantas outras iniciativas desenvolvidas pelo movimento sindical e popular em todo o país.

Para tanto será necessário estabelecer uma consistente política de alianças com todos os setores marginalizados e oprimidos, com a sociedade civil organizada, do campo e da cidade. A articulação com entidades e movimentos sociais do meio rural, são estratégicas. No espaço urbano, torna-se necessário estabelecer relações mais estreitas com as demais entidades sindicais urbanas e um conjunto importante de ONGs.

Deveremos dar um salto de qualidade em nossas ações e estruturas, tendo como eixo central a busca de maior organicidade do conjunto do MSTR para a implementação de experiências práticas de sustentabilidade que propiciem maior visibilidade do potencial da agricultura familiar e sua valorização institucional. 
O MSTR, para atuar de forma eficaz e eficiente na construção do PADRS, precisará também, qualificar e renovar o seu discurso e sua prática. Para tanto é necessário formular e implementar, de forma sistemática, um programa massivo de formação de quadros e uma estratégia eficaz e eficiente de comunicação.

As ações de capacitação para o desenvolvimento local deverão ser a base para este programa, contemplando a formulação e o acompanhamento de planos municipais e regionais de desenvolvimento. E estes devem levar em conta a diversidade e a complexidade dos interesses da nossa base.

A formação profissional é um elemento estratégico para a implementação de qualquer política de desenvolvimento. Deverá constituir um instrumento que ajude os trabalhadores e trabalhadoras rurais a desenvolverem as habilidades e competências necessárias para a implementação desse Projeto Alternativo, usando, entre outros recursos, os do SENAR. Tanto a qualificação quanto a reconversão profissional dos trabalhadores e trabalhadoras serão fundamentais para incorporar concepções que orientem mecanismos diferenciados de desenvolvimento .

\section{Relação entre as reivindicações globais e ações locais}

Um dos principais desafios do movimento sindical atualmente é combinar mudanças nas políticas governamentais - federal e estaduais - e, ao mesmo tempo, organizar as ações de base. As alternativas de desenvolvimento não podem se restringir às reivindicações e mobilizações no âmbito das políticas públicas globais, tampouco às iniciativas exclusivamente locais. A potencialização das alternativas se dá pela capacidade de articular os vários níveis local, estadual, regional e nacional.

As iniciativas locais junto à sociedade no âmbito municipal e intermunicipal deverão ser capazes de dar corpo a um novo perfil de desenvolvimento. A combinação das mobilizações locais com as reivindicações de políticas globais permitirá a participação ampla e a criação de condições efetivas para a "urbanização" do setor rural.

Será necessário, portanto, desenvolver maior capacidade de organizar os recursos locais, direcionando-os para o fortalecimento da organização social. Isto permitirá o aumento da autonomia local na tomada de decisões e o aumento da capacidade de reter e reinvestir capitais. Este desenvolvimento localizado trará maior grau de inclusão social e maior capacidade de regenerar e conservar o meio ambiente.

A utilização dos recursos próprios, combinados com políticas de desenvolvimento global, criará condições efetivas de vida no meio rural, garantindo a permanência e o crescimento das famílias no campo, especialmente dos jovens. Para isso, é imprescindível o redirecionamento das políticas e dos recursos hoje utilizados, assegurando investimentos e implantação de infra-estrutura que garanta qualidade de vida. 
Um Projeto Alternativo de Desenvolvimento Rural Sustentável só poderá ser, portanto, um projeto de alavancagem desses recursos, mobilização de atores sociais e políticos capazes de sensibilizar a sociedade local, se estiver em estreita sintonia com as mudanças institucionais de caráter nacional ou estadual. A concentração das energias do movimento sindical nessa alavancagem exigirá, antes de tudo, o estabelecimento de um frutífero diálogo com a sociedade e mais eficientes negociações com as esferas privadas e governamentais.

\section{A ação sindical local na construção}

\section{de alternativas de desenvolvimento}

Acreditamos que esse projeto de desenvolvimento interessa à maioria da sociedade e todos os atores sociais deverão estar nele envolvidos. Por tal motivo, a mobilização da comunidade será condição imprescindível para o início e perenidade de um desenvolvimento alternativo. As instâncias do MSTR, em especial os STRs e seus parceiros, deverão qualificar a sua atuação para participar ativamente na construção desse desenvolvimento. As ações dos STRs não poderão se dar isoladamente, nem apenas na defesa dos interesses de seus representados, mas deverão propor ações concretas para o conjunto dos movimentos sociais frente à atual realidade econômica e social dos municípios.

Neste sentido, os STRs deverão buscar o desenvolvimento com maior eficiência, estabelecendo parcerias com outras entidades para realizar trabalhos de unidade integrada. Entre elas podemos citar: secretarias municipais de agricultura, órgãos de pesquisa e assistência técnica e extensão rural, escolas públicas e privadas, universidades, igrejas, cooperativas, associações comunitárias e imprensa. Portanto, caberá aos STRs articular o processo de discussão nos municípios, envolvendo outros setores da sociedade, sensibilizando e estimulando tal processo.

O primeiro esforço deverá ser exatamente o de elaborar os projetos de desenvolvimento locais por meio de processos democráticos. A participação popular deverá ser constante, e somente ela assegurará a implementação, efetivação e, principalmente, continuidade das ações, independentemente de quem esteja no governo.

Um instrumento importante a ser utilizado para assegurar o debate e a efetivação de alternativas de desenvolvimento refere-se aos Conselhos Municipais de Desenvolvimento. O desafio será fazer com que estes conselhos constituam, de fato, instrumentos importantes de participação social, garantindo legitimidade política, para que não se transformem em meros instrumentos de manipulação política das autoridades locais.

Além do acompanhamento e atuação junto às Câmaras Municipais e participação nos conselhos municipais, o MSTR deverá atuar também na discussão e definição do processo de planejamento e orçamento municipal, direcionando a 
sua aplicação a serviço do desenvolvimento sustentável: seja por meio dos Orçamentos Participativos, já adotados em muitos municípios, seja por Planos Plurianuais, Lei de Diretrizes Orçamentárias e Lei Orçamentária Anual, que são importantes instrumentos definidos em Constituição Federal, Constituições Estaduais e Leis Orgânicas dos Municípios, que poderão e deverão ter participação direta nos movimentos sociais.

Além desses, outros instrumentos poderão ser implementados com a participação social, assegurando a execução de ações e de programas que se contraponham à atual lógica desenvolvimentista e excludente. O MSTR deverá ser um ator estimulador da comunidade, propondo novas alternativas de desenvolvimento, buscando a retomada da auto-estima da população e o incremento das suas capacidades produtivas e gestão das políticas sociais pelo conjunto da população.

Manoel José dos Santos é presidente da Confederação Nacional dos Trabalhadores na Agricultura (CONTAG). 